\title{
Inconsistency associated with SOX11 immunohistochemistry in mantle cell lymphoma: a meta-analysis
}

\author{
Woojoo Lee ${ }^{1} \cdot$ Eun Shin ${ }^{2} \cdot$ Bo Hyung Kim ${ }^{3,4} \cdot$ Hyunchul Kim $^{2}$ (D)
}

Received: 3 May 2019 / Accepted: 2 July 2019 / Published online: 22 July 2019

(C) Springer-Verlag GmbH Germany, part of Springer Nature 2019

\begin{abstract}
SOX11 immunohistochemistry (IHC) in mantle cell lymphoma (MCL) is known to show varied results. Our aim was to evaluate the factor responsible for this variation among different studies. A meta-analysis was performed with the original data including the proportion and number of SOX11-positive MCL cases, host and clonality of SOX11 antibodies, clone or catalog number of antibodies, MCL subtypes, number of cases with indolent traits, number of aggressive variants, and cut-off for SOX11 IHC interpretation. A total of 21 published studies were analyzed. The combined proportion of SOX11-positive MCL cases was $0.80(95 \% \mathrm{CI}=[0.72,0.87])$, and substantial heterogeneity was observed $\left(I^{2}=83 \%\right)$. To explore sources of heterogeneity, subgroup analysis and meta-regression were done. Subgroup analysis with moderators of antibody clone or catalog number, antibody clonality, and monoclonal antibody clones showed substantial residual heterogeneity. Meta-regression with moderators of the proportion of cut-off value showed statistically significant result, although that with the aggressive cases did not. However, meta-regression with the cut-off value as a moderator showed substantial heterogeneity. The current meta-analysis of SOX11 immunohistochemistry in MCL showed the cut-off value to be important sources of overall heterogeneity.
\end{abstract}

Keywords SOX11 $\cdot$ Immunohistochemistry $\cdot$ Mantle cell lymphoma $\cdot$ Meta-analysis

\section{Introduction}

Mantle cell lymphoma (MCL) is a mature B cell lymphoma with small- to medium-sized tumor cells and CCND1 translocation [1]. In most MCLs, $t(11 ; 14)(\mathrm{q} 13: \mathrm{q} 32)$ translocation between $I G H$ gene and $C C N D 1$ gene results in overexpression

Woojoo Lee and Eun Shin contributed equally to this work.

Hyunchul Kim

hyunchulk@hallym.or.kr

1 Department of Statistics, Inha University, Incheon 22201, Republic of Korea

2 Department of Pathology, Hallym University Dongtan Sacred Heart Hospital, 7, Keunjaebong-gil, Hwaseong-si, Gyeonggi-do 18450, Republic of Korea

3 Department of Clinical Pharmacology and Therapeutics, Kyung Hee University College of Medicine and Hospital, Seoul 02453, Republic of Korea

4 Department of Biomedical Science and Technology, Graduate School, Kyung Hee University, Seoul 02453, Republic of Korea of cyclin D1 [1]. Usual immunophenotype of MCL is BCL2, CD5, and cyclin D1-positive and BCL6, CD10, and CD23negative [1]. However, MCLs with aberrant phenotypes, including CD5-negative or CD10 and BCL6-positive cases, were also reported [1]. In addition, there are cyclin D1negative MCLs that overexpress cyclin D2 or cyclin D3 [1]. The diagnosis of cyclin D1-negative MCLs is performed with SOX11 staining, which is positive for most MCLs, regardless of cyclin D1 overexpression [2].

The transcription factor SOX11 is encoded by SOX11, which is a member of the $S O X$ gene family [3]. The nuclear expression of SOX11 was found to be specific to MCL, compared to that in other types of lymphomas [4]. However, the expression seemed to vary widely with respect to antibodies, and some studies suggested the performance of antibodies or different cut-off values across studies as the reasons of variation in the results $[1,5,6]$. In addition, MCLs with indolent clinical courses, including leukemic non-nodal MCL, small cell variant MCL, and MCLs with aggressive behavior (such as pleomorphic and blastoid variants), tended to show low expression rate of SOX11 $[1,5,7,8]$. Despite the varied 
expressions, objective evaluation of the possible causes has not been performed yet.

In this meta-analysis, we aimed to evaluate the factors causing variation in reported SOX11 expression using subgroup analysis and meta-regression.

\section{Materials and methods}

\section{Published studies and selection criteria}

We searched PubMed, EMBASE, and Cochrane library through May 9, 2018, with the following key words: "SOX11" and ("lymphoma" or "lymphomas"). Reference lists of review articles were also searched. Duplicate data and articles were excluded considering the authors and their affiliations. Original articles were included if SOX11 immunohistochemistry was performed in human MCL cases. When multiple articles from an author or institution were found; the most informative article was selected for the current study. Non-English articles, article or conference abstracts without sufficient information for meta-analysis, review articles, case reports, comments, errata, articles on cell line or animals, and those concerning SOX11 studies with methods other than immunohistochemistry were excluded. The selection process is shown in Fig. 1.

\section{Data extraction}

The following data from all eligible studies were extracted [5-25]: the first author's name, year of publication, number of SOX11-positive MCLs, number of total MCLs, type of MCLs, species and clone of SOX11 antibody, proportion of MCL subtypes (cases with indolent characteristics, and aggressive variants), and cut-off values of SOX11. For cases with indolent characteristics, the following were included:
Fig. 1 Flow diagram of study selection

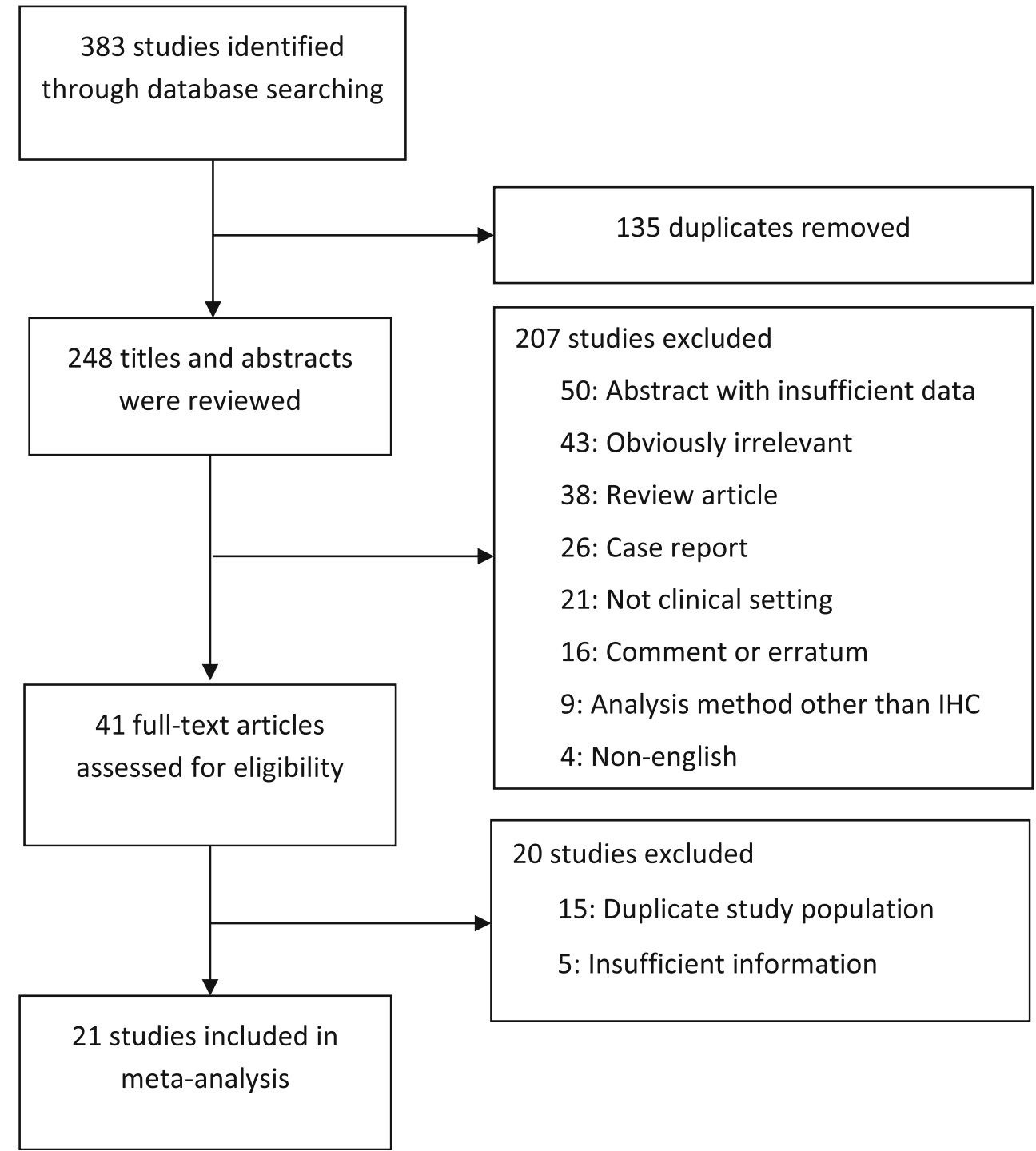




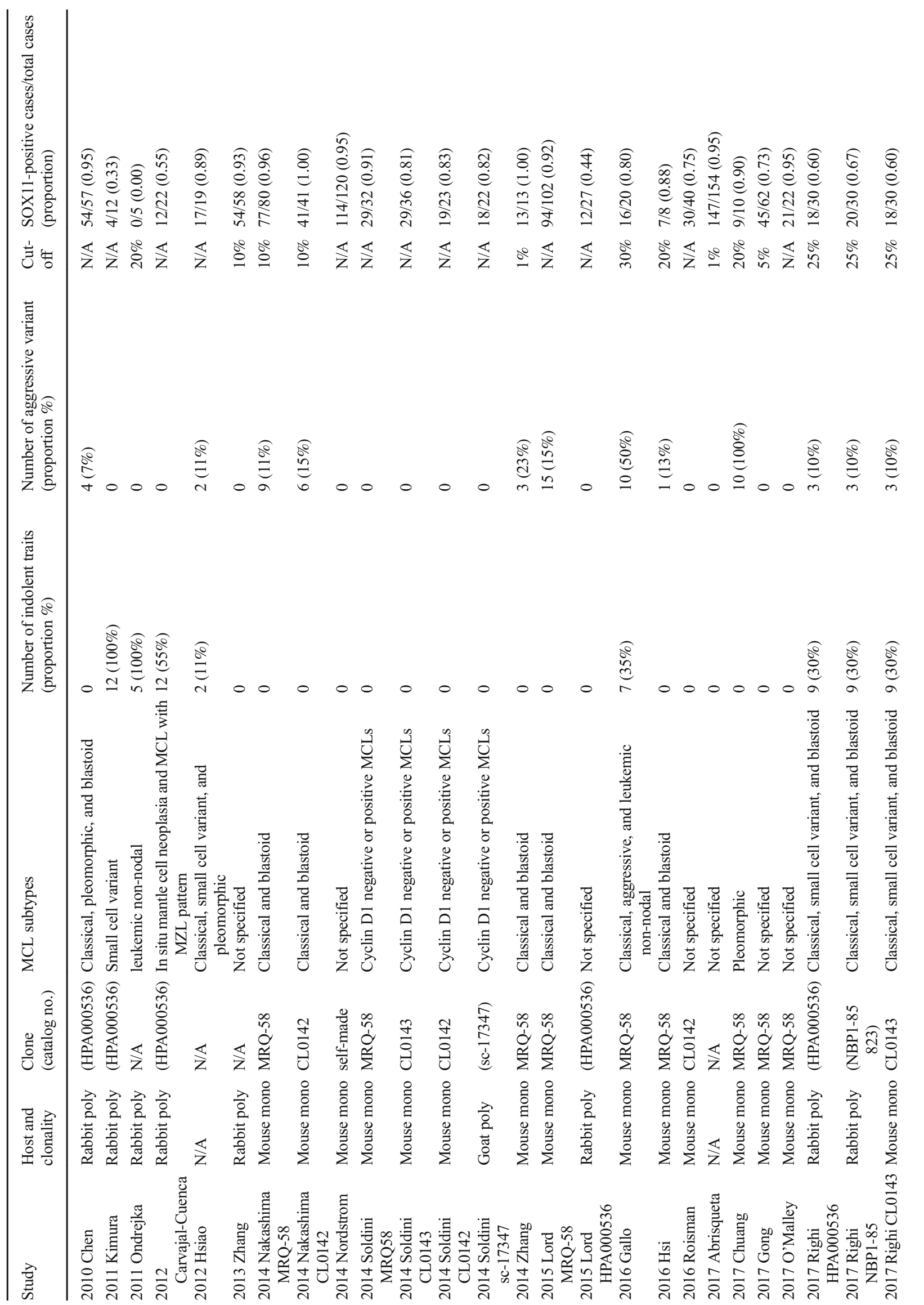


leukemic non-nodal MCL, small cell variant MCL, and MCL with indolent clinical course.

\section{Statistical analyses}

All data were analyzed using $\mathrm{R}$ version 3.4.3, with "meta" package [26, 27]. We investigated logit-transformed proportion of SOX11-positive MCLs as the effect size of each study. Based on random effect models, statistical heterogeneity was evaluated using Higgins' $I^{2}$ statistics. For $I^{2}$ value greater than $40 \%$, the studies in meta-analysis were considered heterogeneous [28]. Subgroup analysis was performed by setting the species and clone of the antibodies as moderators. Metaregression analyses were performed with proportion of indolent cases, proportion of aggressive variants, and cut-off values as covariates. Residual heterogeneity, which could not be explained by the covariates used in the meta-regression, was also considered present for $I^{2}>40 \%$. Publication bias was examined by Egger's test, Thompson's test, rank test, and the test for funnel plot asymmetry based on a linear regression model [29].

\section{Results}

\section{Selection and characteristics of the studies}

Three hundred and eighty-three reports were identified in the database search. A total of 21 studies fulfilled the inclusion criteria [5-25]; all were case-control studies. Four studies used more than one antibody $[5,14,16,18]$. Rabbit polyclonal antibodies were used for eight study populations [5-9, 16, 24]. Mouse monoclonal antibodies were used for 16 [5, 10-12, 14-19, 22, 25]. Goat polyclonal antibody was used for one [18]. Four studies did not specify the species of antibody used [13, 20, 21, 23]. Among the studies with mouse monoclonal antibodies, clone MRQ-58 was used on 10 study populations [5, 10-12, 14-16, 18, 19, 22]. MCLs with indolent traits (leukemic non-nodal MCL, small cell variant MCL, and MCL with indolent clinical course) were included in 10 study populations [7, 9, 11, 13, 16, 20,24]. Aggressive variant MCLs (pleomorphic and blastoid variants) were included in 14 study populations $[5,8,10-14,16,19,20]$. Cut-off value was specified in 14 study populations $[6,10-12,14,16,19$, $21,22,24]$. The proportion of SOX11-positive cases ranged from zero to one (Table 1). For all studies, meta-analysis was performed by using a random effect model.

The combined proportion of SOX11-positive cases was $0.80(95 \% \mathrm{CI}=[0.72,0.87])$. Substantial heterogeneity was observed between the studies, and it means that the reported SOX11-positive rates in MCLs are highly heterogeneous $\left(I^{2}=83 \%\right)$ (Fig. 2). To explore sources of heterogeneity, we considered subgroup analysis and meta-regression as 
discussed in the following sections. Before conducting the analyses, we checked whether there was an evidence of publication bias in our collection of studies. The funnel plot did not show strong evidence of publication bias (Fig. 3), and Egger's test $(p=0.3091)$, Thompson's test $(p=0.2426)$, and rank test $(p=0.3677)$ showed no significant result at 0.05 level [29].

\section{Subgroup analysis}

Subgroup analysis was done to see if any specific group could be the source of heterogeneity. In subgroup analysis, the studies were sectioned into subgroups, and heterogeneity of each was tested. Three categorical variables were considered in subgroup analysis. Due to the limited number of studies, a univariate approach was employed. The first categorical variable was the antibody clone or catalog number. All studies, except six without specified antibody clone or catalog number, were grouped according to their monoclonal antibody clone or polyclonal antibody catalog number $[5,7-12$, 14-19, 22, 25]. HPA000536 and MRQ-58 groups (the number of studies $\geq 2$ ) showed $I^{2}>65 \%$ (Fig. 4). MRQ-58 groups were expected to show low heterogeneity, but all groups showed high heterogeneity, thereby implying heterogeneity to be explored further.

The second categorical variable was the antibody clonality. All studies, except four without specified antibody species, were divided into two groups according to their antibody clonality, rabbit polyclonal, and mouse monoclonal [5-12, 14-19, 22, 24, 25]; subgroup analysis was done in an attempt to explain the source of heterogeneity. Both groups showed high heterogeneity (Fig. 5); the group of mouse monoclonal antibodies showed lower heterogeneity $\left(I^{2}=74 \%\right)$ than the group of rabbit polyclonal antibodies $\left(I^{2}=80 \%\right)$ as expected (Fig. 5).

The third categorical variable was the clone of monoclonal antibodies. Studies with monoclonal antibodies were divided into two groups - those with clone MRQ-58 and the restand subgroup analysis was done to see if the source of heterogeneity could be explained by the monoclonal antibody clone. Both groups showed high heterogeneity. The clone MRQ-58 that was expected to show more homogeneous result actually showed lesser heterogeneity $\left(I^{2}=71 \%\right)$ than that of the rest $\left(I^{2}=81 \%\right)$ (Fig. 6).

All three subgroup analyses did not show any specific group without heterogeneity, and possible source of heterogeneity could not be found.

\section{Meta-regression}

Meta-regression was applied to test whether certain continuous variables could explain the heterogeneous result obtained by utilizing regression analysis method.
Fig. 2 Forest plot of all studies reporting SOX11 immunohistochemistry in mantle cell lymphoma

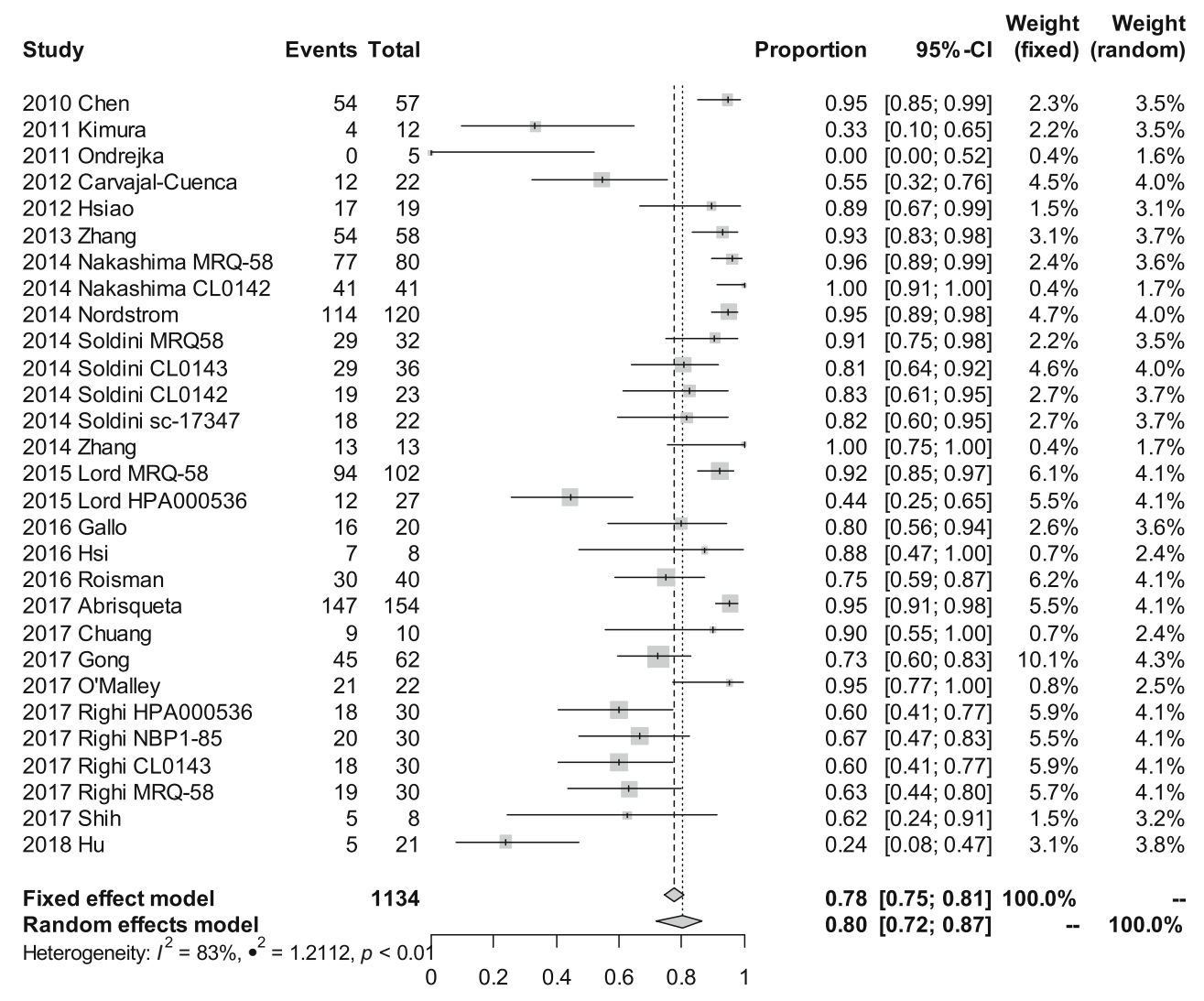


Fig. 3 Funnel plot of metaanalysis for studies reporting SOX11 immunohistochemistry in mantle cell lymphoma. Individual studies are represented by small circles

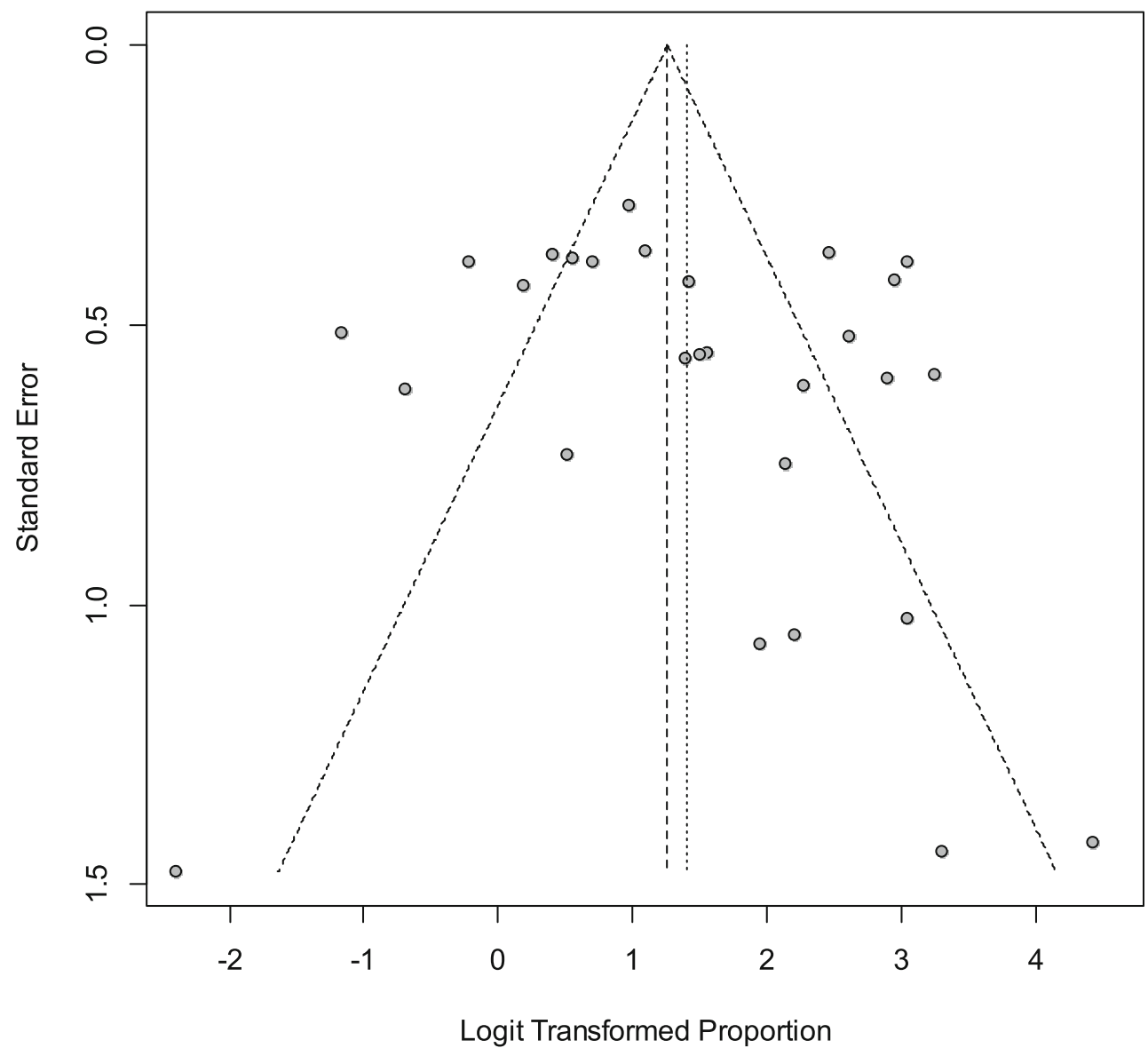

Three continuous covariates were considered in metaregression (Table 2). Due to the limited number of studies, a univariate approach was employed. The first covariate was the proportion of cases with indolent traits. 10 study populations with specified cases of indolent traits were included in the meta-regression $[7,9,11,13,16,20,24]$. Results showed that the proportion of cases with indolent traits was a statistically significant covariate (intercept $=1.51,95 \% \mathrm{CI}=[0.71,2.31]$, $p=0.0002$, slope $=-2.87,95 \% \mathrm{CI}=[-4.60,-1.14], p=$ $0.0012)$. The residual heterogeneity was not substantial $\left(I^{2}=\right.$ $34.91 \%$ ). This result implied statistically significant inverse relation between the proportion of indolent cases and heterogeneity of SOX11-positive rate in MCLs. In other words, the two factors, SOX11-positive rate and proportion of indolent cases, fit into statistically significant regression model. Since residual heterogeneity was low, the proportion of indolent MCL could be regarded as an important source of heterogeneity.

The second covariate was the proportion of aggressive cases. 15 study populations with specified aggressive cases were included in the meta-regression $[5,8$, 10-14, 16, 19, 20]; it did not show statistically significant coefficient (intercept $=1.37,95 \% \mathrm{CI}=[0.42,2.32]$, $p=0.0046$, slope $=0.91,95 \% \mathrm{CI}=[-2.35,4.16], p=$
0.58). The meta-regression showed substantial residual heterogeneity $\left(I^{2}=83.90 \%\right)$.

The third covariate was the cut-off value. 14 study populations with specified cut-off values were included in the metaregression [6, 10-12, 14, 16, 19, 21, 22, 24]; it showed that the cut-off value was statistically significant (intercept $=2.94$, $95 \% \mathrm{CI}=[1.83,4.06], p<0.0001$, slope $=-0.08,95 \%$ $\mathrm{CI}=[-0.14,-0.03], p=0.0037)$. The residual heterogeneity was substantial $\left(I^{2}=72.54 \%\right)$. It suggested the cut-off value as another statistically significant source of heterogeneity showing inverse relation. In other words, the two factors, SOX11 positive rate and cut-off value for SOX11 positivity, fit into statistically significant regression model. However, since the residual heterogeneity is still high, the cut-off value may not be the only source of heterogeneity.

\section{Discussion}

The present meta-analysis evaluated SOX11 immunohistochemistry results in MCL. The estimated overall proportion of SOX11-positive MCL was 0.80, with substantial heterogeneity. As shown by subgroup analysis, substantial heterogeneity still remained after accounting for the individual 


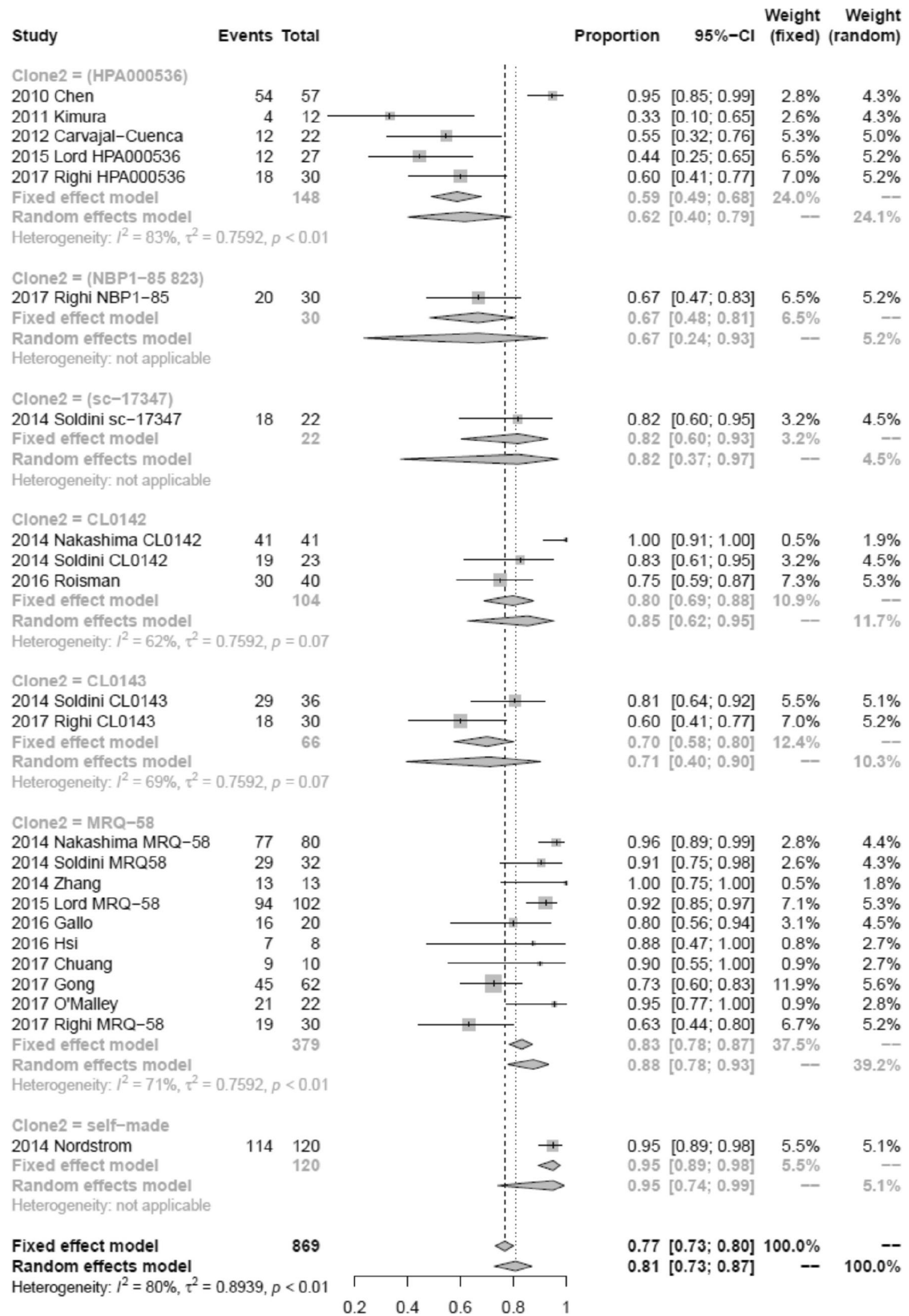

Fig. 4 Forest plot of subgroup analysis by monoclonal antibody clones or polyclonal antibody catalog numbers 


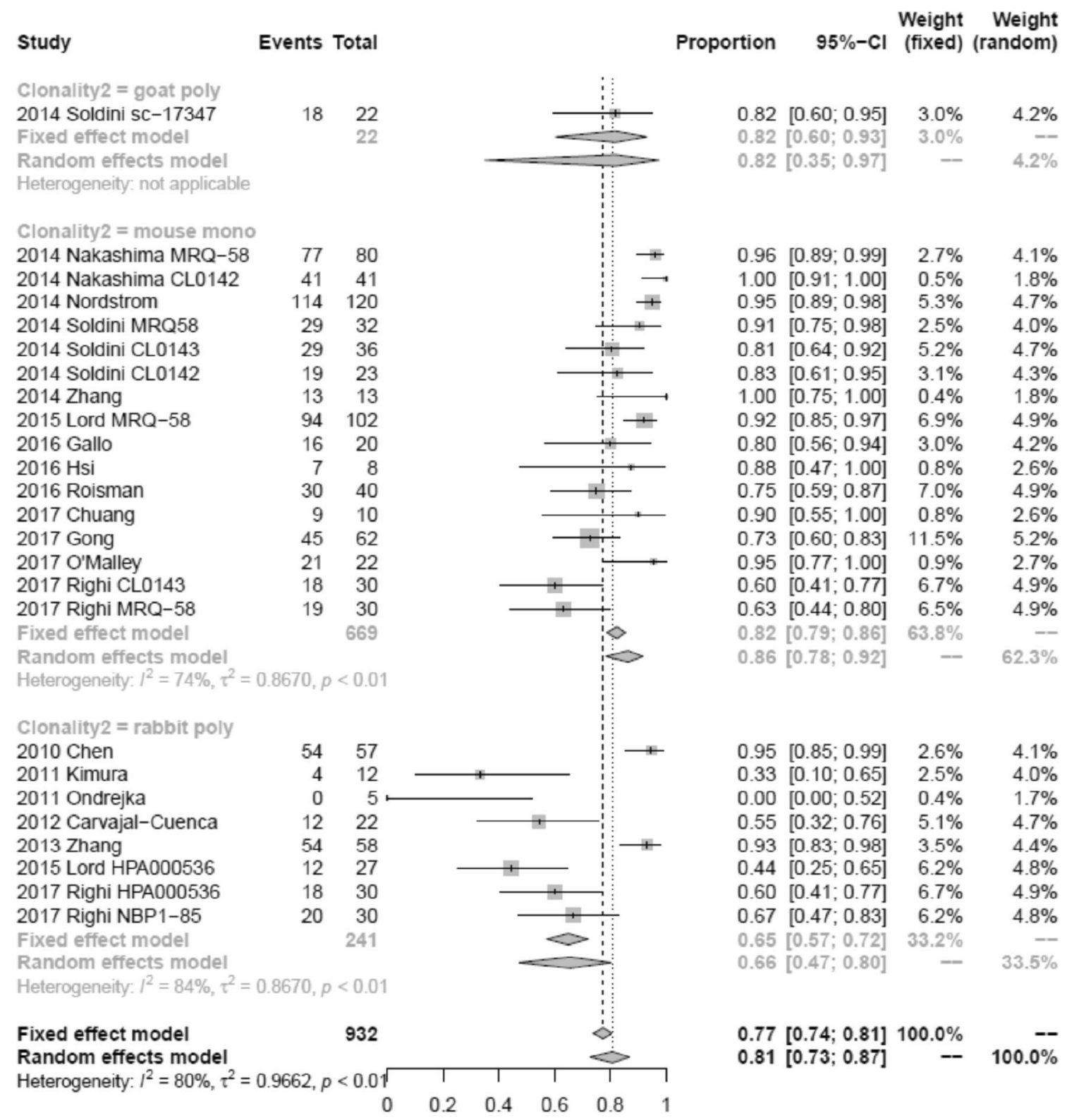

Fig. 5 Forest plot of subgroup analysis by clonality of antibodies

antibody, clonality of the antibodies, and a specific clone among monoclonal antibodies as moderators. Metaregression showed that, unlike the aggressive MCLs, the indolent MCLs and the cut-off value for SOX11 immunohistochemistry explained heterogeneity.

We speculated that the possible causes of heterogeneity were antibodies with different performances, varied cut-off values in immunohistochemistry interpretation, and proportion of indolent or aggressive MCLs. In fact, different performances between rabbit polyclonal and mouse monoclonal antibodies or among different mouse monoclonal antibodies were suspected by researchers [6, 16, 18, 30]. Sensitivity and specificity of a MRQ-58 clone were regarded to be superior to that of other mouse monoclonal antibodies by some authors [5, 10, 14, 16, 18]. The group of MRQ-58 clone showed lesser heterogeneity than the groups of other monoclonal antibodies, though still noticeably high. Evaluating antibody performances was beyond the scope of this study. In addition, certain antibody might actually outperform others. However, at least, there had been no remarkable differences between antibodies with respect to the heterogeneity of SOX11-positive proportion in immunohistochemistry.

Proportion of indolent MCL cases was a statistically significant factor causing heterogeneity. Current WHO classification recognizes such indolent MCLs first, by the subtype category of leukemic non-nodal MCL and second, as a histological variant of the small cell MCL [1]. The WHO classification describes leukemic non-nodal MCL as SOX11- 




Fig. 6 Forest plot of subgroup analysis by clones among mouse monoclonal antibodies ("Clone2 = True" means MRQ-58)

negative tumors [1]. Small cell variant MCLs are shown to be SOX11-negative by some researchers [7, 31]. Some classical MCLs with indolent clinical behavior, but neither leukemic non-nodal nor small cell MCL, are reported to be SOX11negative [9, 31]. Regardless of histopathological classification, they shared small cell histology, negative SOX11 staining, and indolent clinical behavior. Since most of the MCLs with indolent traits were SOX11-negative, we expected the indolent MCLs to be an important factor contributing to the heterogeneity in the overall analysis of SOX11 immunohistochemistry, as also supported by our meta-regression results.

Proportion of aggressive MCL cases did not affect heterogeneity among the studies. Studies on SOX11 expression in MCL reported some pleomorphic and blastoid MCLs to be SOX11-negative [4, 5, 8, 19].
Therefore, there was a possibility that the proportion of aggressive MCL cases, included in the studies considered for this meta-analysis, caused heterogeneity. However, the proportion of aggressive MCLs was not shown to be a statistically significant cause of heterogeneity.

SOX11-negative aggressive MCLs might cause potential confusion with cyclin D1-positive diffuse large B cell lymphoma (DLBCL), since there is no clear definition regarding such cases with aggressive histological feature, positive cyclin D1, and negative SOX11 immunohistochemistry. Currently, the main available choice in diagnostic approaches in such cases is the CCND1 translocation test [13, 32]. However, many of cyclin D1-negative MCLs lacked CCND1 translocation, and

Table 2 Meta-regression with covariates of the proportion of indolent and aggressive cases, and of the cut-off value for SOX11

\begin{tabular}{|c|c|c|c|c|c|c|c|}
\hline \multirow[t]{2}{*}{ Covariate } & \multicolumn{3}{|c|}{ Coefficient } & \multicolumn{3}{|l|}{ Intercept } & \multirow[t]{2}{*}{$I^{2}(\%)$} \\
\hline & Estimate & $P$ value & $95 \% \mathrm{CI}$ & Estimate & $P$ value & $95 \% \mathrm{CI}$ & \\
\hline Proportion of indolent cases & -2.87 & 0.0012 & -4.60 to -1.14 & 1.51 & 0.0002 & 0.71 to 2.31 & 34.91 \\
\hline Proportion of aggressive cases & 0.91 & 0.58 & -2.35 to 4.16 & 1.37 & 0.0046 & 0.42 to 2.32 & 83.90 \\
\hline Cut-off value & -0.08 & 0.0037 & -0.14 to -0.03 & 2.94 & $<0.0001$ & 1.83 to 4.06 & 72.54 \\
\hline
\end{tabular}


harbored $C C N D 2$ or $C C N D 3$ translocations instead [33, 34]. In this context, SOX11 can be used as a tumor marker, and one study included in this meta-analysis actually used SOX11 as a determining factor [10]. With the emergence of SOX11 as a relatively new diagnostic marker, the definition of DLBCL, MCL, and their subtypes might need to be revisited.

The cut-off value used for interpretation of SOX11 immunohistochemistry was suspected to be a potential source of variable SOX11 immunostaining, as seen in a previous report [5] as well as suggested by our metaregression. Since the different cut-off values adopted by each author cause heterogeneity, a single well-defined cut-off threshold for SOX11 immunohistochemical interpretation might provide consistent results for SOX11 immunostaining in MCL.

Regarding the cut-off value, SOX11 mRNA and protein expression had been correlated in several earlier studies $[5,14,17,18,30,31,35]$; most of them showed good correlation between RT-PCR and immunohistochemistry results $[14,17,30,31,35]$. One study had reported that SOX11 mRNA-negative cases showed complete absence of immunohistochemistry-positive cells, whereas mRNA-positive cases showed at least weak immunostaining in most cells [18]. Another study proposed that weak and variable SOX11 staining may be regarded as positive [5]. Based on these studies, the possible optimal cut-off for SOX11 immunohistochemistry should be low. However, since even normal lymph node showed a few scattered positive cells, extremely low number of positive cells might best be ignored [5].

Our current meta-analysis was limited by the relatively small number of published studies considered. Especially, a meta-regression, using the three covariates together, could not be performed since only few articles recorded all the covariates. In the near future, it will be necessary for researchers to make their studies more reproducible by providing full details on the dataset.

In conclusion, this meta-analysis of SOX11 immunohistochemistry in MCL suggested the indolent MCLs and the cut-off value as important sources of overall heterogeneity, whereas antibody and aggressive cases were not. Although SOX11 is recognized as a marker for MCL, its practical application is not as wellaccepted as cyclin D1. Defining cut-off values for SOX11 immunohistochemistry in MCL is expected to facilitate robust results and wider use of the antibody in the diagnosis of lymphoma.

Author's contributions W. L.: data analysis and manuscript editing E. S.: article selection, data extraction, and manuscript editing

B. K.: article selection and data extraction

H. K.: design and manuscript editing
Funding Information Woojoo Lee was supported by a Grant from the Next-Generation BioGreen 21 program (Project No. PJ01337701), Rural Development Administration, Republic of Korea.

\section{Compliance with ethical standards}

Conflict of interest The authors declare that they have no conflict of interest.

\section{References}

1. Swerdlow SH (2017) WHO classification of tumours of haematopoietic and lymphoid tissues. World Health Organization classification of tumours, Revised fourth edition. International Agency for Research on Cancer. WHO Press, Lyon, France. Geneva, Switzerland

2. Mozos A, Royo C, Hartmann E, De Jong D, Baro C, Valera A, Fu K, Weisenburger DD, Delabie J, Chuang SS, Jaffe ES, RuizMarcellan C, Dave S, Rimsza L, Braziel R, Gascoyne RD, Sole F, Lopez-Guillermo A, Colomer D, Staudt LM, Rosenwald A, Ott G, Jares P, Campo E (2009) SOX11 expression is highly specific for mantle cell lymphoma and identifies the cyclin D1-negative subtype. Haematologica 94(11):1555-1562. https://doi.org/10.3324/ haematol.2009.010264

3. Jay P, Goze C, Marsollier C, Taviaux S, Hardelin JP, Koopman P, Berta P (1995) The human SOX11 gene: cloning, chromosomal assignment and tissue expression. Genomics 29(2):541-545. https://doi.org/10.1006/geno.1995.9970

4. Ek S, Dictor M, Jerkeman M, Jirstrom K, Borrebaeck CA (2008) Nuclear expression of the non B-cell lineage Sox11 transcription factor identifies mantle cell lymphoma. Blood 111(2):800-805. https://doi.org/10.1182/blood-2007-06-093401

5. Lord M, Wasik AM, Christensson B, Sander B (2015) The utility of mRNA analysis in defining SOX11 expression levels in mantle cell lymphoma and reactive lymph nodes. Haematologica 100(9):e369e372. https://doi.org/10.3324/haematol.2015.123885

6. Zhang LN, Cao X, Lu TX, Fan L, Wang L, Xu J, Zhang R, Zou ZJ, Wu JZ, Li JY, Xu W (2013) Polyclonal antibody targeting SOX11 cannot differentiate mantle cell lymphoma from B-cell nonHodgkin lymphomas. Am J Clin Pathol 140(6):795-800. https:// doi.org/10.1309/AJCPEBOUJ7GVYVLG

7. Kimura Y, Sato K, Imamura Y, Arakawa F, Kiyasu J, Takeuchi M, Miyoshi H, Yoshida M, Niino D, Sugita Y, Morito T, Yoshino T, Nakamura S, Ohshima K (2011) Small cell variant of mantle cell lymphoma is an indolent lymphoma characterized by bone marrow involvement, splenomegaly, and a low Ki-67 index. Cancer Sci 102(9):1734-1741. https://doi.org/10.1111/j.1349-7006.2011. 01988.x

8. Chen YH, Gao J, Fan G, Peterson LC (2010) Nuclear expression of sox11 is highly associated with mantle cell lymphoma but is independent of $\mathrm{t}(11 ; 14)(\mathrm{q} 13 ; \mathrm{q} 32)$ in non-mantle cell B-cell neoplasms. Mod Pathol 23(1):105-112. https://doi.org/10.1038/modpathol. 2009.140

9. Carvajal-Cuenca A, Sua LF, Silva NM, Pittaluga S, Royo C, Song JY, Sargent RL, Espinet B, Climent F, Jacobs SA, Delabie J, Naresh KN, Bagg A, Brousset P, Warnke RA, Serrano S, Harris NL, Swerdlow SH, Jaffe ES, Campo E (2012) In situ mantle cell lymphoma: clinical implications of an incidental finding with indolent clinical behavior. Haematologica 97(2):270-278. https://doi.org/10. 3324/haematol.2011.052621

10. Chuang WY, Chang H, Chang GJ, Wang TH, Chang YS, Wang TH, Yeh CJ, Ueng SH, Chien HP, Chang CY, Wan YL, Hsueh C (2017) Pleomorphic mantle cell lymphoma morphologically mimicking 
diffuse large B cell lymphoma: common cyclin D1 negativity and a simple immunohistochemical algorithm to avoid the diagnostic pitfall. Histopathology 70(6):986-999. https://doi.org/10.1111/his. 13161

11. Gallo M, Cacheux V, Vincent L, Bret C, Tempier A, Guittard C, Mace A, Leventoux N, Costes V, Szablewski V (2016) Leukemic non-nodal mantle cell lymphomas have a distinct phenotype and are associated with deletion of PARP1 and 13q14. Virchows Archiv 469(6):697-706. https://doi.org/10.1007/s00428-016-2016-8

12. Hsi AC, Hurley MY, Lee SJ, Rosman IS, Pang X, Gru A, Schaffer A (2016) Diagnostic utility of SOX11 immunohistochemistry in differentiating cutaneous spread of mantle cell lymphoma from primary cutaneous B-cell lymphomas. J Cutan Pathol 43(4):354-361. https://doi.org/10.1111/cup.12668

13. Hsiao SC, Cortada IR, Colomo L, Ye H, Liu H, Kuo SY, Lin SH, Chang ST, Kuo TU, Campo E, Chuang SS (2012) SOX11 is useful in differentiating cyclin D1-positive diffuse large B-cell lymphoma from mantle cell lymphoma. Histopathology 61(4):685-693. https://doi.org/10.1111/j.1365-2559.2012.04260.x

14. Nakashima MO, Durkin L, Bodo J, Lin J, Quintanilla-Martinez L, Fu K, Hsi ED (2014) Utility and diagnostic pitfalls of SOX11 monoclonal antibodies in mantle cell lymphoma and other lymphoproliferative disorders. Appl Immunohistochem Mol Morphol 22(10):720-727. https://doi.org/10.1097/pai.0000000000000067

15. O'Malley DP, Lee JP, Bellizzi AM (2017) Expression of LEF1 in mantle cell lymphoma. Ann Diagn Pathol 26:57-59. https://doi.org/ 10.1016/j.anndiagpath.2016.09.016

16. Righi S, Pileri S, Agostinelli C, Bacci F, Spagnolo S, Sabattini E (2017) Reproducibility of SOX-11 detection in decalcified bone marrow tissue in mantle cell lymphoma patients. Hum Pathol 59: 94-101. https://doi.org/10.1016/j.humpath.2016.09.018

17. Roisman A, Huaman Garaicoa F, Metrebian F, Narbaitz M, Kohan D, Garcia Rivello H, Fernandez I, Pavlovsky A, Pavlovsky M, Hernandez L, Slavutsky I (2016) SOXC and MiR17-92 gene expression profiling defines two subgroups with different clinical outcome in mantle cell lymphoma. Genes Chromosom Cancer 55(6): 531-540. https://doi.org/10.1002/gcc.22355

18. Soldini D, Valera A, Sole C, Palomero J, Amador V, Martin-Subero JI, Ribera-Cortada I, Royo C, Salaverria I, Bea S, Gonzalvo E, Johannesson H, Herrera M, Colomo L, Martinez A, Campo E (2014) Assessment of SOX11 expression in routine lymphoma tissue sections: characterization of new monoclonal antibodies for diagnosis of mantle cell lymphoma. Am J Surg Pathol 38(1):8693. https://doi.org/10.1097/PAS.0b013e3182a43996

19. Zhang YH, Liu J, Dawlett M, Guo M, Sun X, Gong Y (2014) The role of SOX11 immunostaining in confirming the diagnosis of mantle cell lymphoma on fine-needle aspiration samples. Cancer Cytopathol 122(12):892-897. https://doi.org/10.1002/cncy.21465

20. Hu Z, Sun Y, Schlette EJ, Tang G, Li S, Xu J, Yin CC, Young KH, Patel KP, Miranda RN, Goswami M, Wang M, Jorgensen JL, Medeiros LJ, Wang SA (2018) CD200 expression in mantle cell lymphoma identifies a unique subgroup of patients with frequent IGHV mutations, absence of SOX11 expression, and an indolent clinical course. Mod Pathol 31(2):327-336. https://doi.org/10. 1038/modpathol.2017.135

21. Abrisqueta P, Scott DW, Slack GW, Steidl C, Mottok A, Gascoyne RD, Connors JM, Sehn LH, Savage KJ, Gerrie AS, Villa D (2017) Observation as the initial management strategy in patients with mantle cell lymphoma. Ann Oncol 28(10):2489-2495. https://doi. org/10.1093/annonc/mdx333

22. Gong Y, Zhang X, Chen R, Wei Y, Zou Z, Chen X (2017) Cytoplasmic expression of C-MYC protein is associated with risk stratification of mantle cell lymphoma. PeerJ 5:e3457. https://doi. org/10.7717/peerj.3457

23. Shih AR, Bledsoe JR, McKelvie P, Louissaint A, Harris NL, Zukerberg L (2017) CD5-negative mantle cell lymphoma shows a less aggressive outcome and variable SOX11 staining. J Hematop 10(2):49-53. https://doi.org/10.1007/s12308-017-0292-0

24. Ondrejka SL, Lai R, Smith SD, Hsi ED (2011) Indolent mantle cell leukemia: a clinicopathological variant characterized by isolated lymphocytosis, interstitial bone marrow involvement, kappa light chain restriction, and good prognosis. Haematologica 96(8):11211127. https://doi.org/10.3324/haematol.2010.036277

25. Nordstrom L, Sernbo S, Eden P, Gronbaek K, Kolstad A, Raty R, Karjalainen ML, Geisler C, Ralfkiaer E, Sundstrom C, Laurell A, Delabie J, Ehinger M, Jerkeman M, Ek S (2014) SOX11 and TP53 add prognostic information to MIPI in a homogenously treated cohort of mantle cell lymphoma-a Nordic Lymphoma Group study. Br J Haematol 166(1):98-108. https://doi.org/10.1111/bjh.12854

26. Core Team R (2017) R: A Language and Environment for Statistical Computing. R Foundation for Statistical Computing, Vienna

27. Schwarzer G (2007) meta: an R package for meta-analysis. R News 7(3):40-45

28. Deeks JJ, Higgins JPT, Altman DG (editors). Chapter 9: Analysing data and undertaking meta-analyses. In: Higgins JPT, Green S (editors). Cochrane Handbook for Systematic Reviews of Interventions Version 5.1.0 (updated March 2011). The Cochrane Collaboration, 2011. Available from https://www.handbook. cochrane.org. Retrieved 31 Jan 2019

29. Thompson SG, Sharp SJ (1999) Explaining heterogeneity in metaanalysis: a comparison of methods. Stat Med 18(20):2693-2708

30. Nordstrom L, Andreasson U, Jerkeman M, Dictor M, Borrebaeck C, Ek S (2012) Expanded clinical and experimental use of SOX11 using a monoclonal antibody. BMC Cancer 12:269. https://doi.org/ 10.1186/1471-2407-12-269

31. Fernandez V, Salamero O, Espinet B, Sole F, Royo C, Navarro A, Camacho F, Bea S, Hartmann E, Amador V, Hernandez L, Agostinelli C, Sargent RL, Rozman M, Aymerich M, Colomer D, Villamor N, Swerdlow SH, Pileri SA, Bosch F, Piris MA, Montserrat E, Ott G, Rosenwald A, Lopez-Guillermo A, Jares P, Serrano S, Campo E (2010) Genomic and gene expression profiling defines indolent forms of mantle cell lymphoma. Cancer Res 70(4): 1408-1418. https://doi.org/10.1158/0008-5472.can-09-3419

32. Zeng W, Fu K, Quintanilla-Fend L, Lim M, Ondrejka S, Hsi ED (2012) Cyclin D1-negative blastoid mantle cell lymphoma identified by SOX11 expression. Am J Surg Pathol 36(2):214-219. https://doi.org/10.1097/PAS.0b013e318241f050

33. Wlodarska I, Dierickx D, Vanhentenrijk V, Van Roosbroeck K, Pospisilova H, Minnei F, Verhoef G, Thomas J, Vandenberghe P, De Wolf-Peeters C (2008) Translocations targeting CCND2, CCND3, and MYCN do occur in $\mathrm{t}(11 ; 14)$-negative mantle cell lymphomas. Blood 111(12):5683-5690. https://doi.org/10.1182/ blood-2007-10-118794

34. Salaverria I, Royo C, Carvajal-Cuenca A, Clot G, Navarro A, Valera A, Song JY, Woroniecka R, Rymkiewicz G, Klapper W, Hartmann EM, Sujobert P, Wlodarska I, Ferry JA, Gaulard P, Ott G, Rosenwald A, Lopez-Guillermo A, Quintanilla-Martinez L, Harris NL, Jaffe ES, Siebert R, Campo E, Bea S (2013) CCND2 rearrangements are the most frequent genetic events in cyclin D1(-) mantle cell lymphoma. Blood 121(8):1394-1402. https://doi.org/ 10.1182/blood-2012-08-452284

35. Cao X, Fan L, Fang C, Zhu DX, Dong HJ, Wang DM, Wang YH, Xu W, Li JY (2012) The expression of SOX11, cyclin D1, cyclin D2, and cyclin D3 in B-cell lymphocytic proliferative diseases. Med Oncol (Northwood, London, England) 29(2):1190-1196. https://doi.org/10.1007/s12032-011-9937-5

Publisher's note Springer Nature remains neutral with regard to jurisdictional claims in published maps and institutional affiliations. 